\title{
Ionospheric turbulence from TEC variations and VLF/LF transmitter signal observations before and during the destructive seismic activity of August and October 2016 in Central Italy
}

\author{
Michael E. Contadakis*,1, Demetrios. N. Arabelos ${ }^{1}$, George N. Vergos ${ }^{1}$, \\ Christos Skeberis ${ }^{2}$, Tomas D. Xenos ${ }^{2}$, Pierfrancesco Biagi ${ }^{3}$, Emmanuel M. Scordilis ${ }^{4}$ \\ (1) Department of Geodesy and Surveying, Aristotle University of Thessaloniki, Greece \\ (2) Department of Electrical \& Computer Engineering, Aristotle University of Thessaloniki, Thessaloniki, Greece \\ (3) Department of Physics, University of Bari, Bari, Italy \\ (2) Department of Geophysics, Aristotle University of Thessaloniki, Greece
}

Article history: received June 23, 2018; accepted July 3, 2019

\begin{abstract}
In this paper we investigate the ionospheric turbulence from observations of TEC variations as well as from VLF/LF transmitter signal observations before and during the disastrous seismic activity of August and October 2016 in Central Italy. The Total Electron Content (TEC) data of 8 Global Positioning System (GPS) stations of the EUREF network, which are being provided by IONOLAB (Turkey), were analysed using Discrete Fourier Analysis in order to investigate the TEC variations. The data acquired for VLF/LF signal observations are from the receiver of Thessaloniki $(40.59 \mathrm{~N}$, 22,78E), Greece, which monitor the VLF/LF transmitters of the International Network for Frontier Research on Earthquake Precursors (INFREP). A method of normalization according to the distance between the receiver and the transmitter is applied on the above data and then they are processed by the Hilbert Huang Transform (HHT) to produce the corresponding spectra for visual analysis. The results of both methods indicate that the High- Frequency limit fo, of the ionospheric turbulence content, increases as the site and the moment of the earthquake occurrence is approaching, pointing to the earthquake locus.
\end{abstract}

Keywords: Seismicity, Ionospheric turbulence, VLF/LF transmission, Brownian walk, Hilbert Huang transform.

\section{Introduction}

It is argued that tectonic activity during the earthquake preparation period produces anomalies at the ground level which propagate upwards in the troposphere as Acoustic or Standing gravity waves [Miyaki et al., 2002; Hayakawa et al., 2011; Hayakawa, 2011; Hayakawa et al., 2018]. These Acoustic or Gravity waves affect the turbidity 


\section{Michael E. Contadakis et al.}

of the lower ionosphere, where sporadic Es-layers may appear too, and the turbidity of the F layer. Subsequently the produced disturbance starts to propagate in the ionosphere's waveguide as gravity wave. The inherent frequencies of the acoustic or gravity wave range between $0.003 \mathrm{~Hz}$ (period $\approx 5 \mathrm{~min}$ ) and $0.0002 \mathrm{~Hz}$ (period $\approx$ $100 \mathrm{~min})$ ), which according to Molchanov et al. [2004, 2006] correspond to the frequencies of the turbulent produced by tectonic activity during the earthquake preparation period. During this propagration the higher frequencies are progressively dumped. Thus observing the frequency content ot the ionospheric turbidity we will observe a decrease of the higher limit of the turbitity frequency band.

In this paper we investigate the ionospheric turbulence from the observations of TEC variations as well as from VLF/LF transmitter signal observations before and during the disastrous seismic activity of August and October 2016 in Central Italy. The Total Electron Content (TEC) data of 8 Global Positioning System (GPS) stations of the EUREF network, which are being provided by IONOLAB (Turkey), were analysed using Discrete Fourier Analysis in order to investigate the TEC variations [Contadakis et al., 2009; Contadakis et al., 2012; Contadakis et al., 2015]. The data acquired for VLF/LF signal observations are from the receiver of Thessaloniki (40.59N, 22.78E), Greece [Skeberis et al., 2015] which monitor the VLF/LF transmitters of the International Network for Frontier Research on Earthquake Precursors (INFREP). A method of normalization according to the distance between the receiver and the transmitter is applied on the above data and then they are processed by the Hilbert Huang Transform (HHT) to produce the corresponding spectra for visual analysis.

\section{Seismotectonic Information of Central Italy}

A series of strong earthquakes struck central Italy within a two months period during 2016, causing human losses and extensive damage in constructions. The excited area is located close to the center of the Apennines mountain belt, a well-known seismically active formation that extends in a NW-SE direction. This seismically active zone was formed during Miocene-Pliocene due to the subduction of Adriatic microplate beneath Eurasia (Italian peninsula) [e.g. Selvaggi and Amato, 1992; Amato et al., 1993; Sparkman et al., 1993; Scandone 1996 among many others]. Later, during Quaternary, the stress regime turn to extensional striking in an almost ENE-WSW direction and developing a series of normal faults along the Apennines mountain belt [e.g. Patacca et al., 1990; Kruse and Royden, 1994; Cinque et al., 1993, D’ Agostino et al., 2001]. This chain of normal faults is responsible for the generation of the recent strong earthquakes of August and October of 2016 (24 August, $\mathrm{M}=6.2 ; 26$ October, $\mathrm{M}=6.1 ; 30$ October, $\mathrm{M}=6.6$ ) that occurred close to the center of Apennines belt.

The map of Figure 1 gives a picture of the seismicity of the Central Apennine belt where the recent activity took place. In this map are plotted the epicenters of all known earthquakes with $M \geq 3.0$ which occurred since 1900 . Black ellipse delimits the seismogenic region of the Amatrice seismic sequence with its three strong ( $M>6.0)$ shocks. In the same map are shown the epicenters of other three strong events that occurred in the broader area since the beginning of the $20^{\text {th }}$ century (see Table 1 ). The focal parameters are mainly adopted from the on-line earthquake catalog of the International Seismological Centre ISC, http://www.isc.ac.uk. All magnitudes are given in the moment magnitude scale, $\mathrm{M}_{\mathrm{w}}$, and are either adopted (when original estimations were available) or estimated by applying proper relations converting other magnitude scales to $\mathrm{M}_{\mathrm{w}}$ [Scordilis, 2006; Tsampas, 2006; Duni et al., 2010].

\begin{tabular}{ccccccc} 
Year & Month & Day & Or. Time & Lat (ON) & Lon (0E) & Mw \\
\hline 1915 & January & 13 & $06: 52$ & 42.00 & 13.50 & 7.0 \\
\hline 1997 & September & 26 & $09: 40$ & 43.09 & 12.82 & 6.0 \\
\hline 2009 & April & 6 & $01: 32$ & 42.37 & 13.32 & 6.3 \\
\hline 2016 & August & 24 & $01: 36$ & 42.71 & 13.17 & 6.2 \\
\hline 2016 & October & 26 & $19: 18$ & 42.96 & 13.07 & 6.1 \\
\hline 2016 & October & 30 & $06: 40$ & 42.86 & 13.09 & 6.6 \\
\hline
\end{tabular}

Table 1. Focal parameters of the six strongest earthquakes than occurred close to the seismogenic region of the Amatrice sequence since 1900 . 


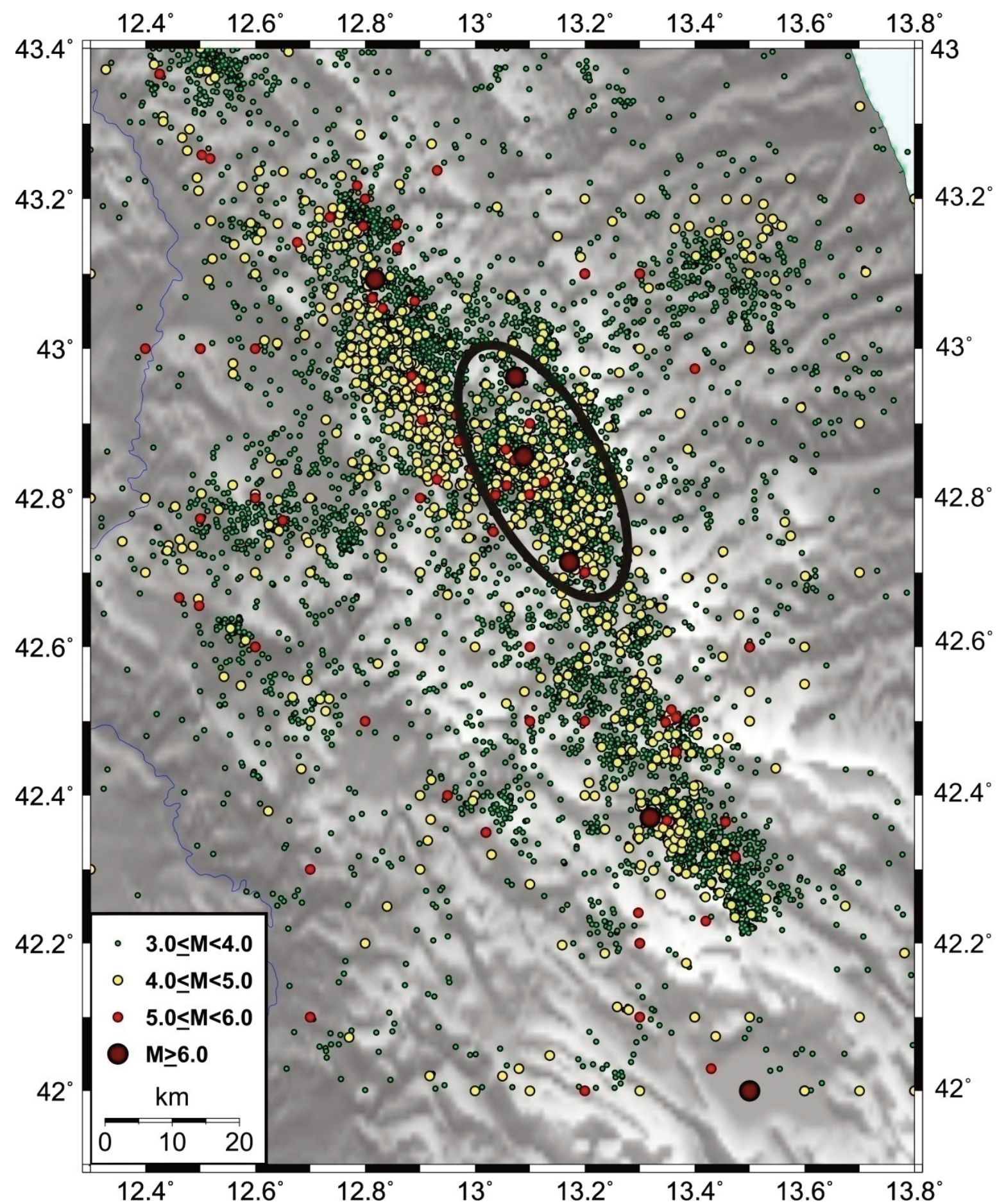

Figure 1. Epicenters of all known earthquakes with $M>3.0$ that occurred during the period 1900-2016 (October) in the broader area of central-northern Apennines. The black ellipse delimits the seismogenic region of the recent(August-October 2016) Amatricesequence.

The Amatrice seismic sequence was generated on a NW-SE oriented (and dipping to the SW) system of normal faults. According to GCMT (Global Centroid Moment Tensor project, http://www.globalcmt.org) the activated segment that gave the strongest earthquake of the sequence (October 30, 06:40, M=6.6) strikes in N149 direction and dips to the SW at an angle of $38^{0}$. The seismogenic region that is formed by the epicenters of the aftershocks (see figure 1) delineates a presumable fault zone of a length of $\sim 30 \mathrm{~km}$, justifying the generation of a characteristic earthquake of magnitude $\mathrm{M} \sim 6.6$ [according to Papazachos et al., 2004]. 


\section{TEC variation over mid latitude Europe}

In the following we investigate the variations of TEC over the broader area of central Italy before and during the seismic activity of of August and October , 2016. To this purpose we use the TEC estimates provided by IONOLAB (http://www.ionolab.org) [Arikan et al., 2009] for 8 mid latitude GPS stations of EUREF which cover epicentre distances from the active area ranging from $382 \mathrm{~km}$ to $2285 \mathrm{~km}$ for the time periods between $24 / 07 / 2016$ to 25/09/2016 and 25/10/2016 to 25/11/2016. The selected GPS stations have about the same latitude and are expected to be affected equally from the Equatorial Anomaly as well as from the Auroral storms. Table 2 displays the 8 EUREF stations while Figure 4 displays the locus of the eight GPS stations and the main shock. The IONOLAB TEC estimation system uses a single station receiver bias estimation algorithm, IONOLAB-BIAS, to obtain daily and monthly averages of receiver bias and is successfully applied to both quiet and disturbed days of the ionosphere for station position at any latitude. In addition, TEC estimations with high resolution are also possible [Arikan et al., 2009]. IONOLAB system provides comparison graphs of its TEC estimations with the estimations of the other TEC providers of IGS in its site. In this work only TEC estimations in perfect accordance among all providers were used. The TEC values are given in the form of a Time Series with a sampling gap (resolution) of 2.5 minutes. Figures 2 and 3 display the TEC variation over the 8 EUREF stations for the time periods between 24/07/2016 to 25/09/2016 and 25/10/ 2016 to 25/11/2016, respectively.

\begin{tabular}{cccc} 
GPS Site & Latitude Degree & Longitude Degree & \multicolumn{1}{c}{ Distancekm } \\
Amatrice & 42.611679 & 13.289436 & 0.0 \\
\hline Toulouse & 43.609253 & 1.444428 & 967.1 \\
\hline Marseille & 43.299892 & 5.370561 & 648.7 \\
\hline Ajaccio & 41.919228 & 8.738636 & 382.3 \\
\hline Matera & 40.667267 & 16.604712 & 350.2 \\
\hline Ohrid & 41.123657 & 20.801771 & 643.4 \\
\hline Sofia & 42.699718 & 23.322260 & 820.0 \\
\hline Bucharest & 44.430111 & 26.103037 & 1051.6 \\
\hline Zelenchukskaya & 43.857071 & 41.585293 & 2285.3 \\
\hline
\end{tabular}

Table 2. Distance of GPS stations from the epicenter of the earthquake.

\subsection{Geomagnetic and Solar activity indices}

The variations of the geomagnetic field were followed by the Dst- index and the planetary kp three hour indices quoted from the site of the Space Magnetism Faculty of Science, Kyoto University (http://swdcwww.kugi.kyotou.ac.jp/index.html) for the time period of our data. Figures 5 and 6 displays the Dst-index variations on August and October of 2016, respectively.

\subsection{Fast Fourier Transform Analysis}

The Power Spectrum of TEC variations will provide information on the frequency content of them. Apart of the well known and well expressed tidal variations, for which the reliability of their identification can be easily inferred by statistical tests, small amplitude space-temporal transient variations cannot have any reliable identification by means of a statistical test. Nevertheless looking at the logarithmic power spectrum we can recognize from the slop of the diagram whether the contributed variations to the spectrum are random or periodical. If they are random the slop will be 0 , which correspond to the white noise, or -2 which correspond to the Brownian walk, otherwise the slop will be different the socalled Fractal Brownian walk [Turcotte, 1997]. This means that we can trace the presence of periodical variations in the logarithmic power spectrum of TEC variations. 


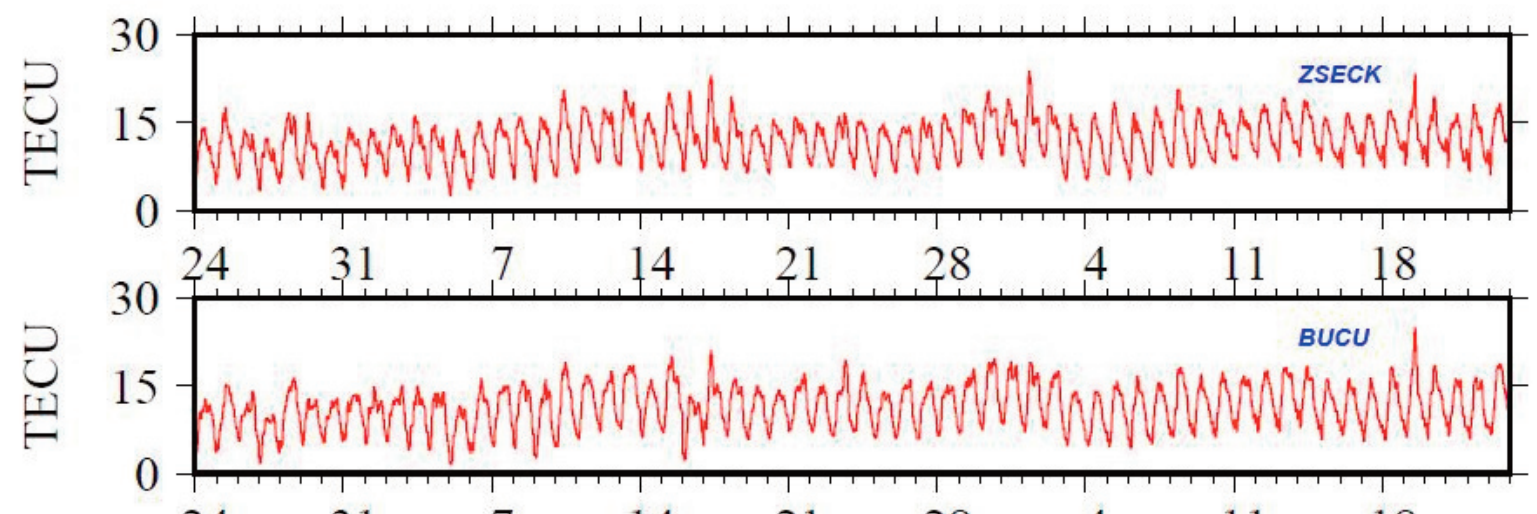

$\underbrace{2}_{0} \begin{aligned} & 30 \\ & 25\end{aligned}$

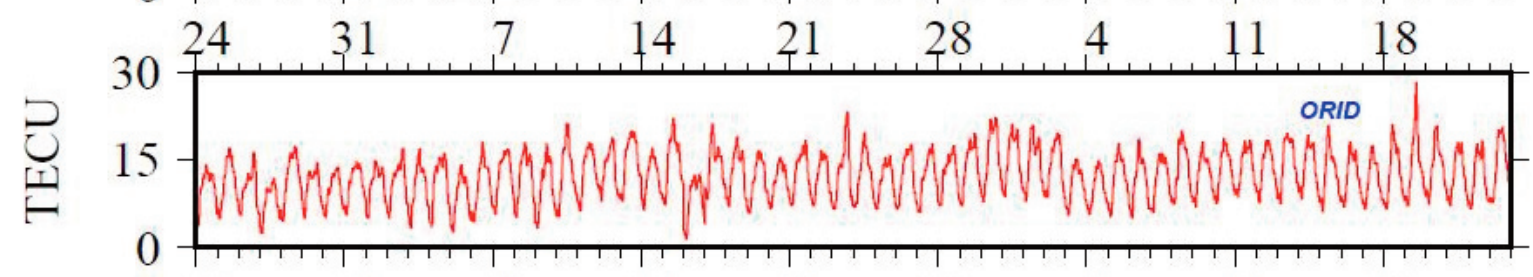

$\underbrace{2}_{0} \begin{aligned} & 30 \\ & 25\end{aligned}$

$\underbrace{2}_{0} \begin{aligned} & 30 \\ & 25\end{aligned}$

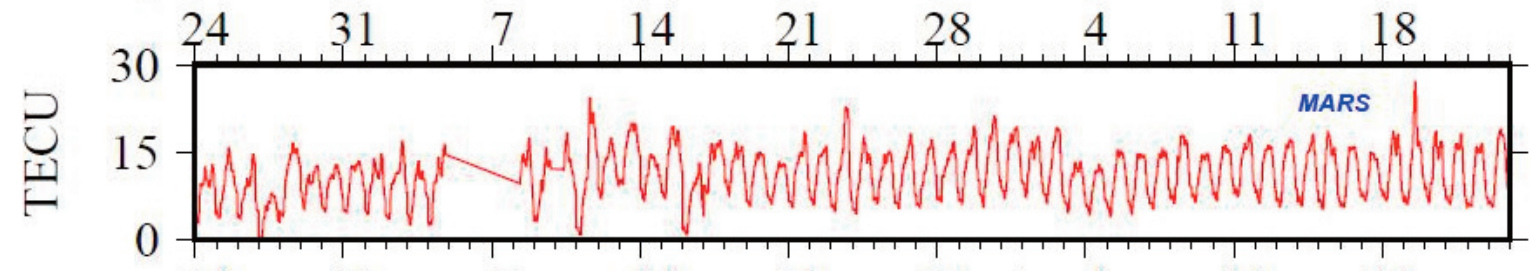

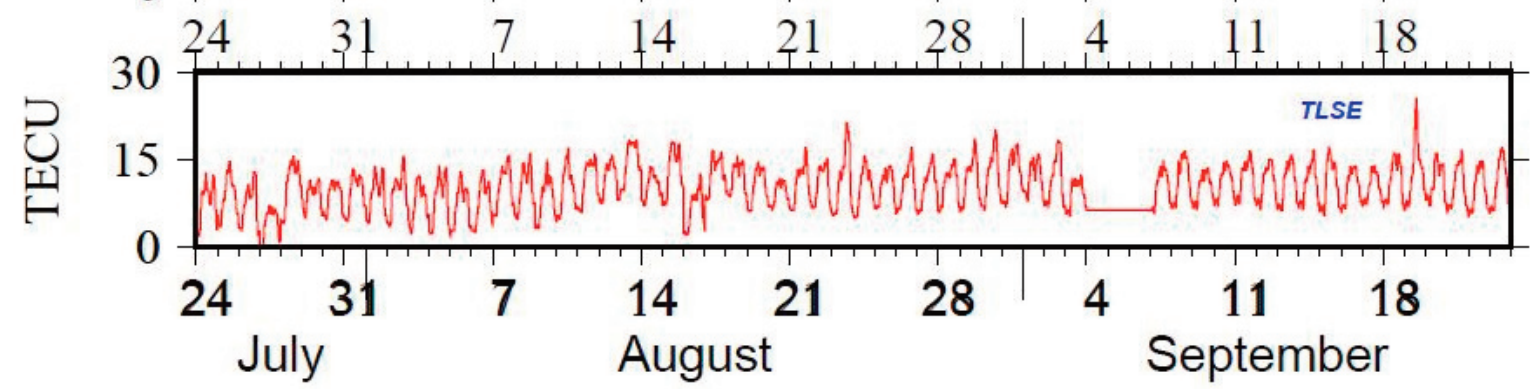

Figure 2. The variations of TEC over the 8 EUREF stations during the time period of 24/07/ 2016 to 25/09/2016. 
Michael E. Contadakis et al.
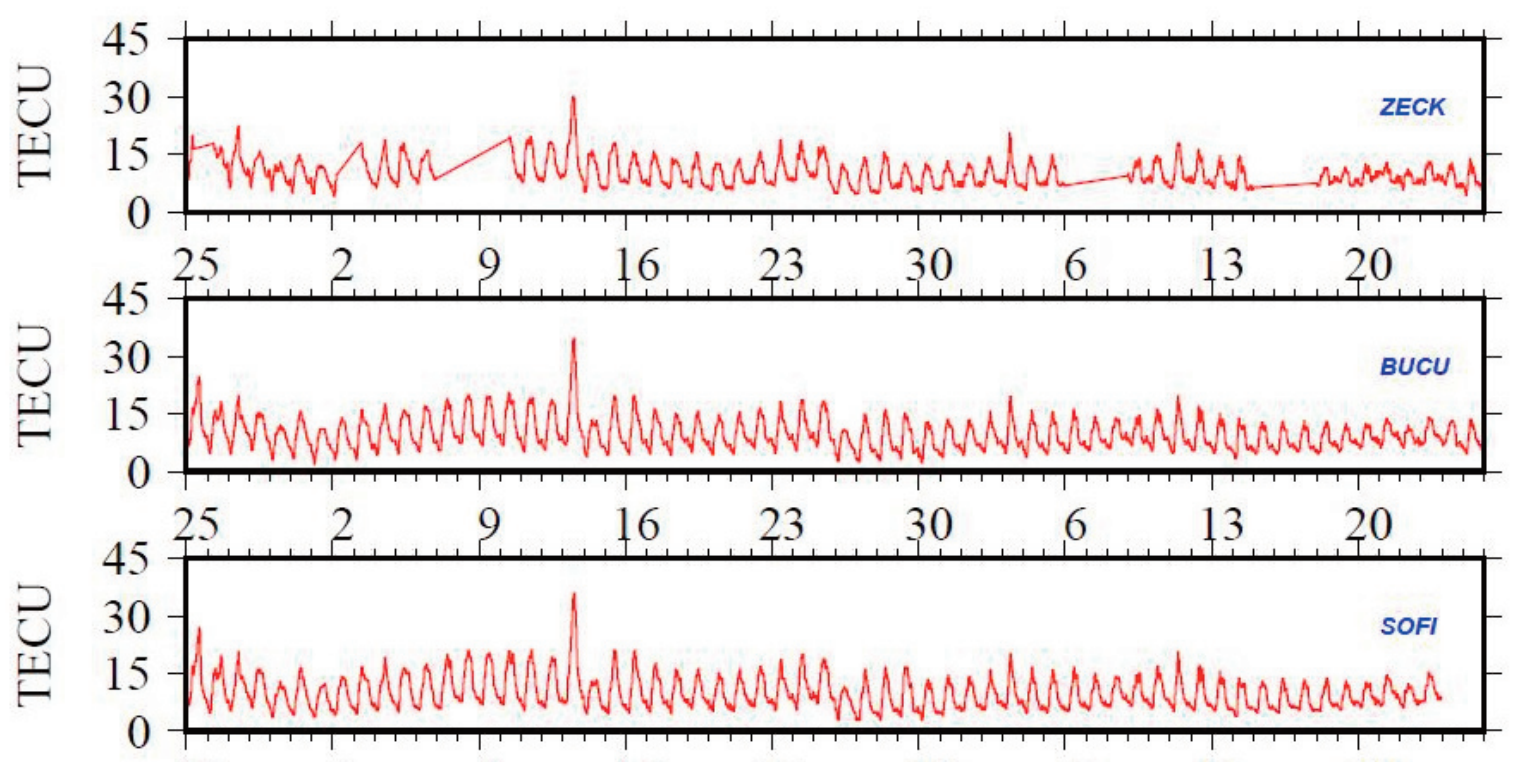

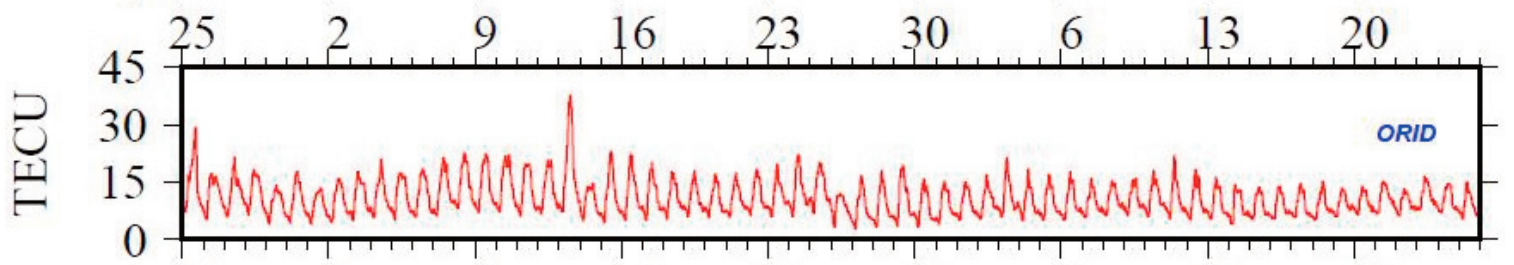

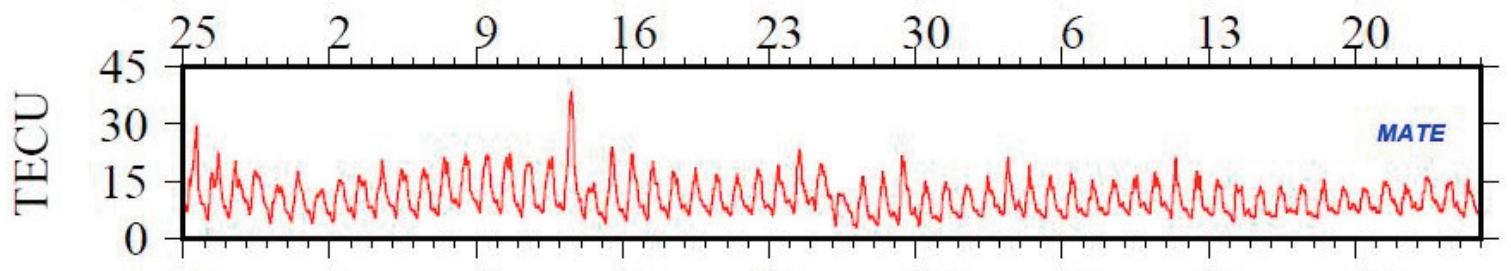

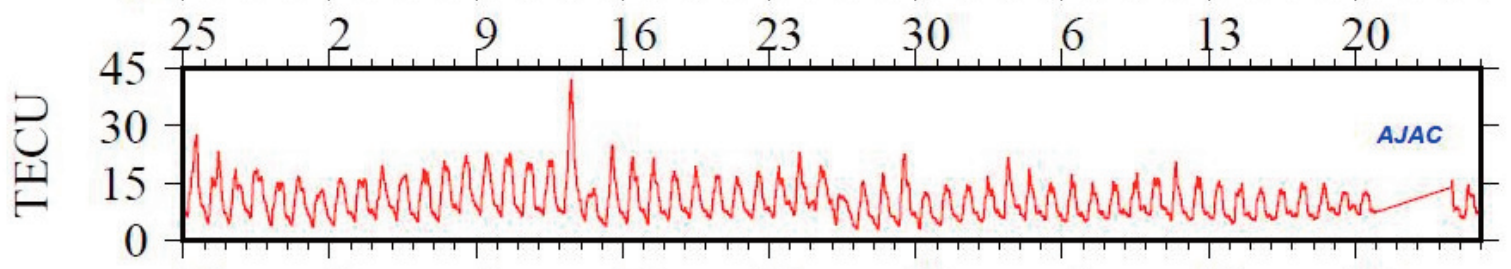

导 $\begin{aligned} & 45 \\ & F\end{aligned}$

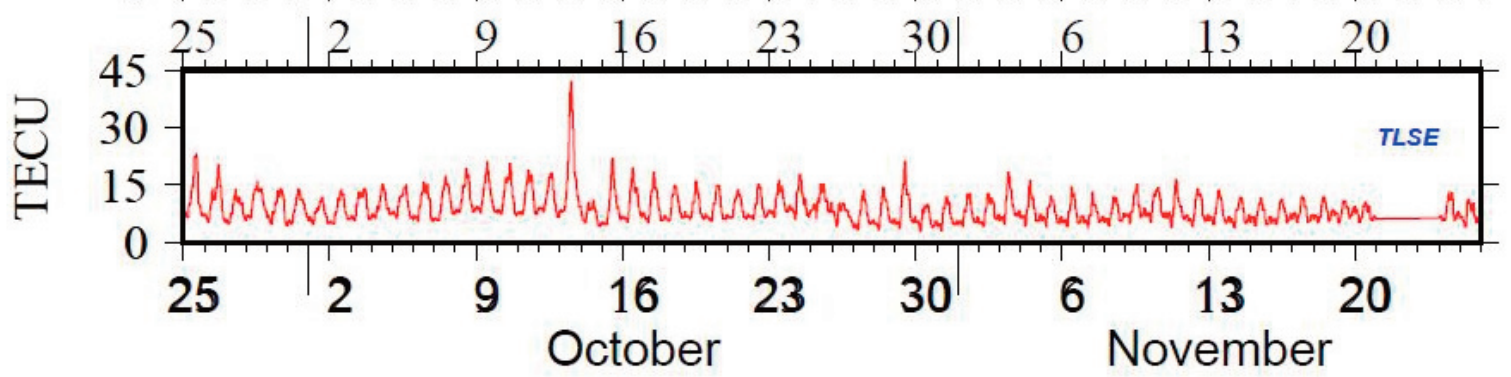

Figure 3. The variations of TEC over the 8 EUREF stations during the time period of 25/10/ 2016 to 25/11/2016. 


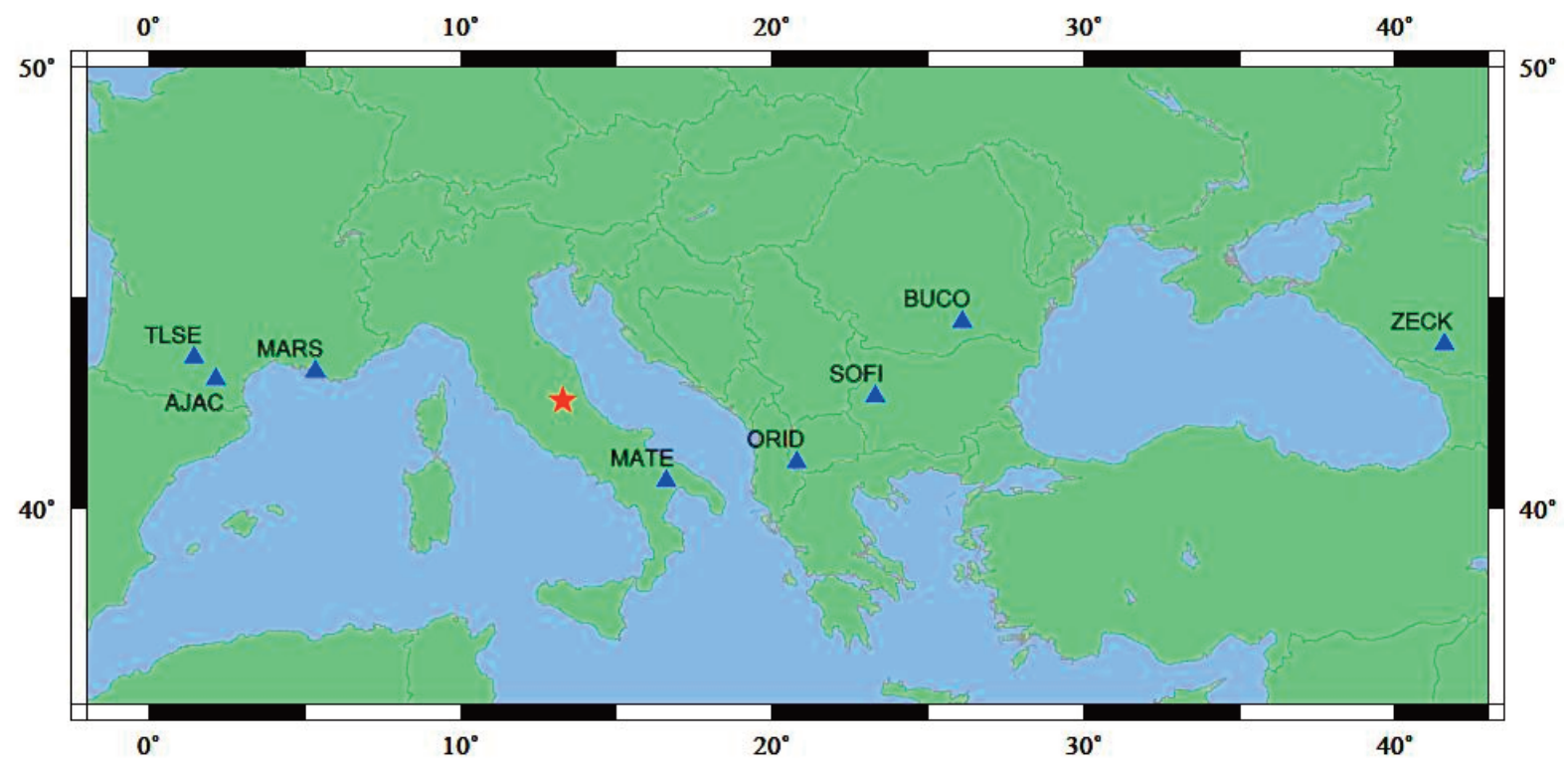

Figure 4. The locus of the GPS stations of the network (in blue) and the locus of the earthquakes of August and October , 2016 (in red).

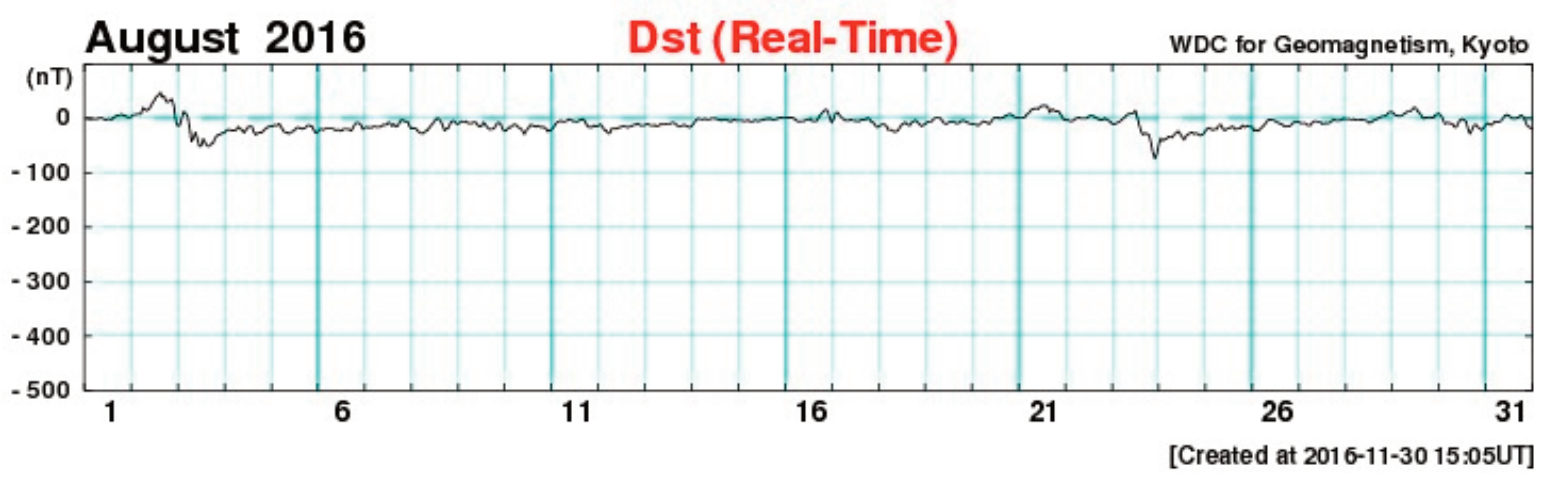

Figure 5. 5 Dst-index variations on August of 2016.

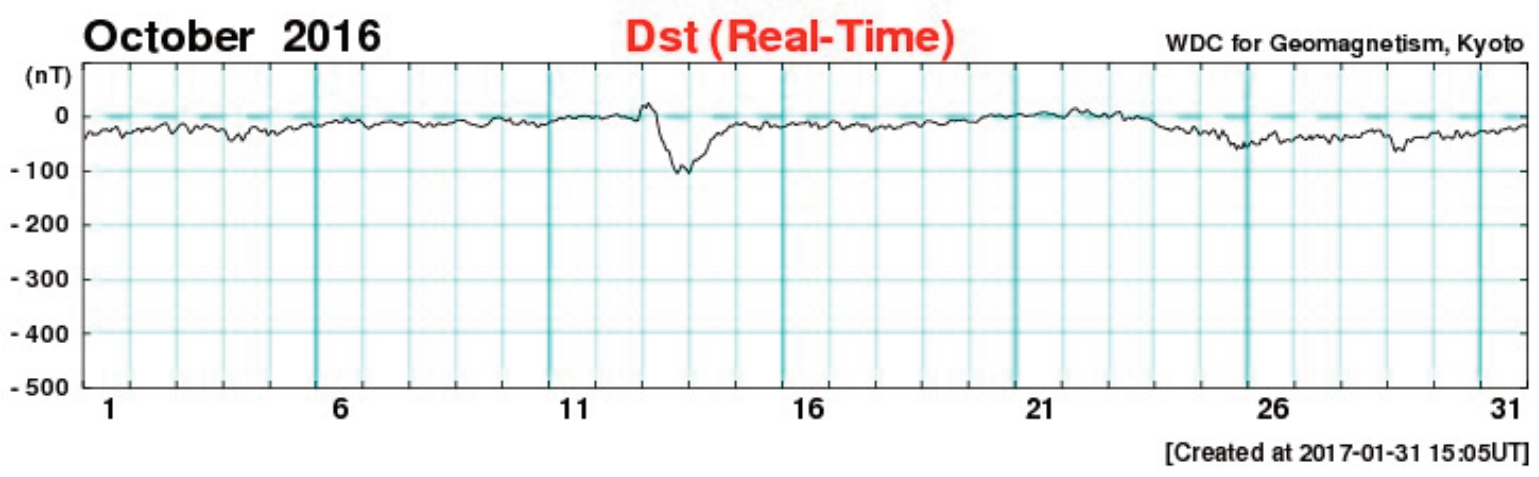

Figure 6. 5 Dst-index variations on October of 2016. 


\section{Michael E. Contadakis et al.}

This method was successfully applied in our previous work [Contadakis et al., 2008; Contadakis et al., 2012; Contadakis et al., 2015] in order to find the frequency content of TEC turbidity. It is realized that the upper frequency limit $f_{o}$ of the spectrum of TEC variations increases as we approach the source of the ionospheric turbidity modulation, in our case the earthquake preparation activity.

\subsection{Results}

Figures 7 and 8 display the variation of TEC turbulence frequency limit fo over the selected EUREF GPS stations for the shock of 24 Augoust and the same show Figures 9 and 10 for the shocks of 26/30 October, 2016. All graphs indicate time and space convergence of increasing turbulene frequency limit $\mathrm{f}_{\mathrm{o}}$ to the earthquakes of 24 August and 26/30 October, occurrence. Hobarat et al. [2005] in a study on the ionospheric turbulence in Low latitudes concluded that the attribution of the turbulence to earthquake process and not to other sources, i.e. solar activity, storms etc is not conclusive. Never the less in our case, the steady monotonic, time and space, convergence of the frequency limit $f_{o}$ increment, to the occurrence of the Amatrice earthquakes of 24/08 and 26\&30/10 is a strong decisive indication that the observed turbidity is generated by the respective earthquakes preparation processes.

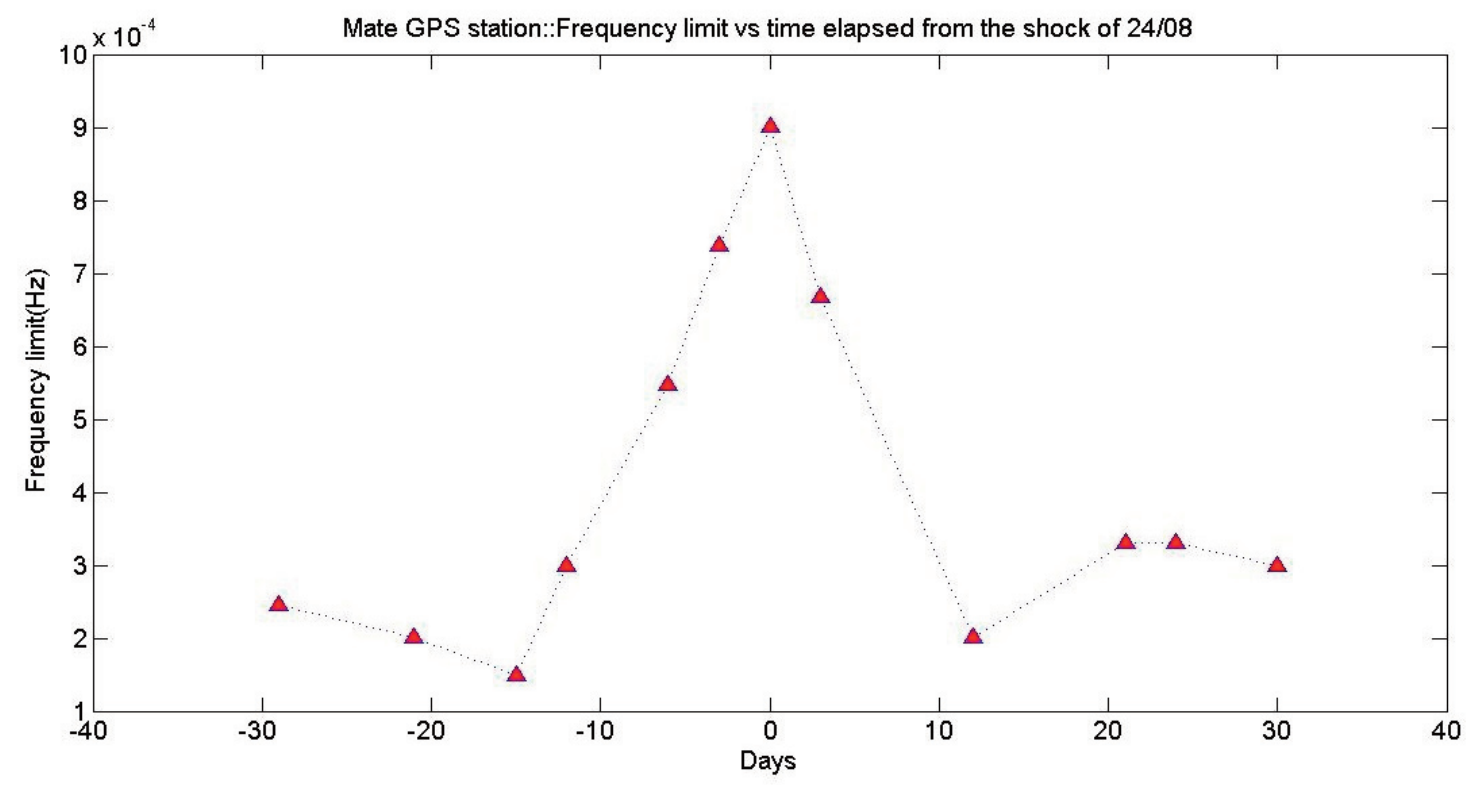

Figure 7. Variation of TEC turbulence frequency limit fo over the closest to Amatrice GPS Stations of Matera, with the time distance from the day of the earthquake of 24 August,2016 occurrence.

The qualitative explanation of this phenomenology can be offered on the basis of the LAIC: Tectonic activity during the earthquake preparation period produces anomalies at the ground level which propagate upwards in the troposphere as Acoustic or Standing gravity waves [Miyaki et al., 2002; Hayakawa et al., 2011; Hayakawa, 2011; Hayakawa et al., 2018]. These Acoustic or Gravity waves affect the turbidity of the lower ionosphere, where sporadic Es-layers may appear too, and the turbidity of the $\mathrm{F}$ layer. Subsequently the produced disturbance starts to propagate in the ionosphere's waveguide as gravity wave and the inherent frequencies of the acoustic or gravity wave can be traced on TEC variations (i.e. the frequencies between $0.003 \mathrm{~Hz}$ (period $\approx 5 \mathrm{~min}$ ) and $0.0002 \mathrm{~Hz}$ (period $\approx 100 \mathrm{~min}$ )), which according to Molchanov et al. [2004, 2006] correspond to the frequencies of the turbulent induced by the LAIC coupling process to the ionosphere. As we move far from the disturbed point, in time or in space, the higher frequencies (shorter wavelength) variation are progressively attenuated. 


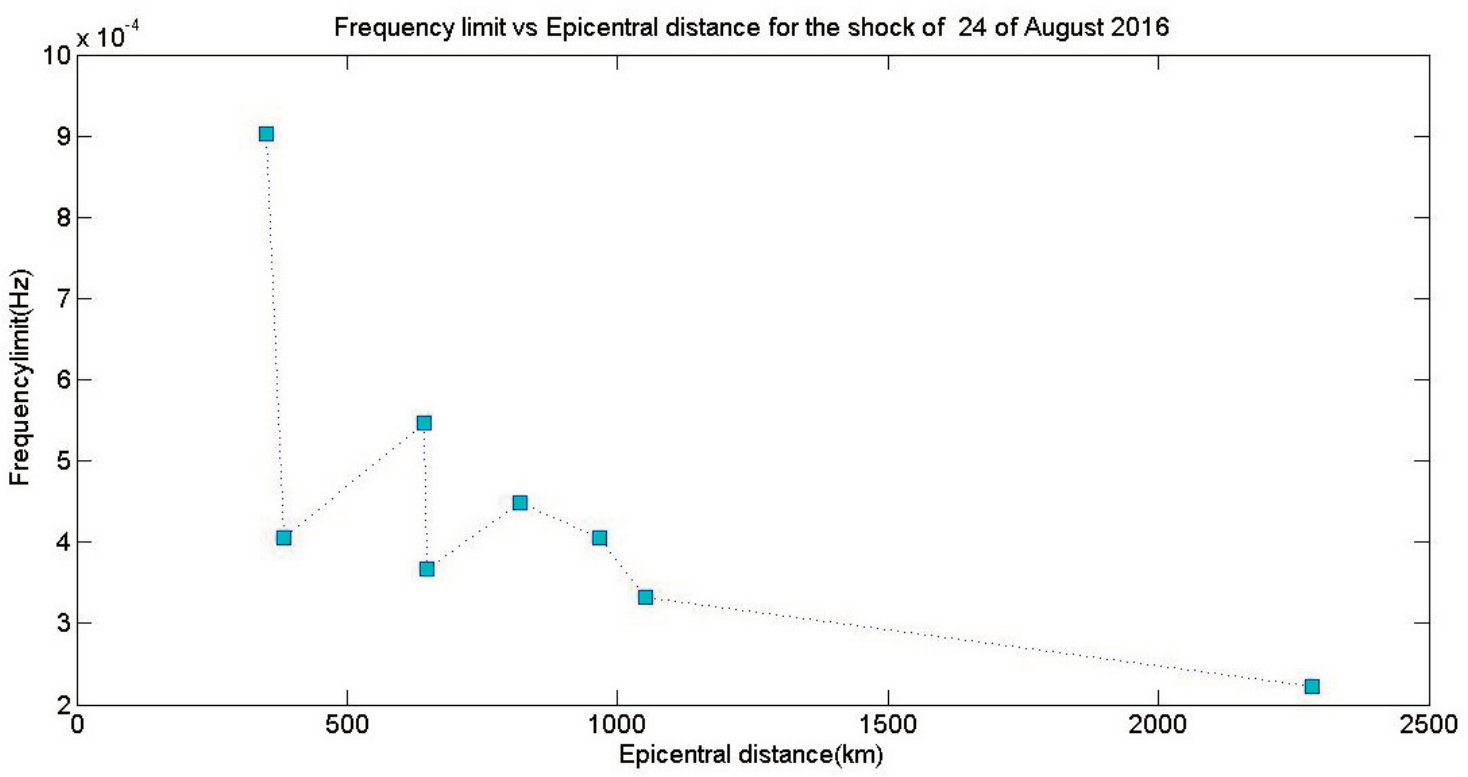

Figure 8. . Variation of TEC turbulence frequency limit fo over the GPS Stations of EUREF, with the epicentral distance around the day of the earthquake of 24 August, 2016 occurrence.

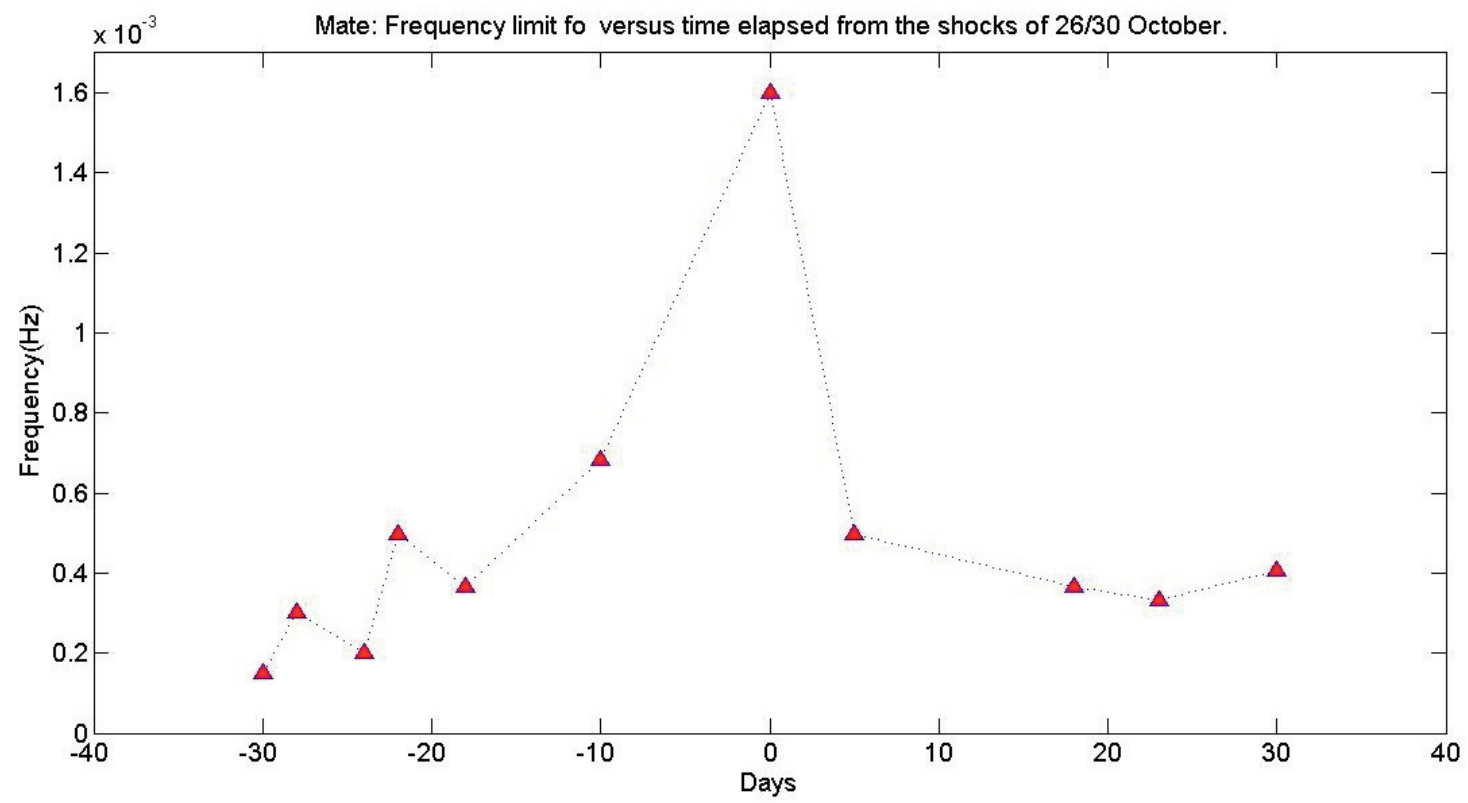

Figure 9. Variation of TEC turbulence frequency limit fo over the closest to Amatrice GPS Stations of Matera, with the time distance from the day of the earthquake of 26/30 October, 2016 occurrence. 
Michael E. Contadakis et al.

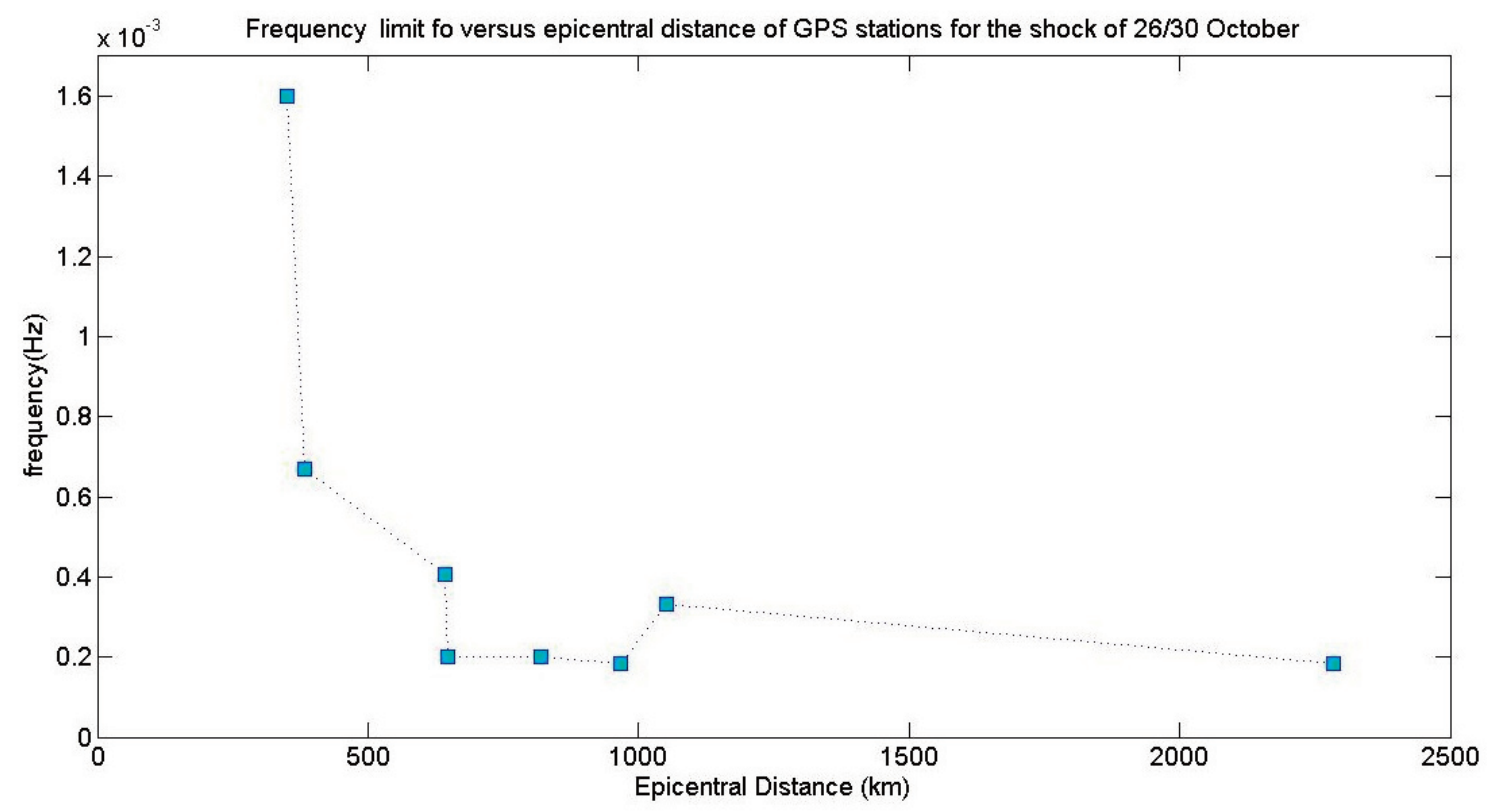

Figure 10. Variation of TEC turbulence frequency limit fo over the GPS Stations of EUREF, with the epicentral distance around the day of the earthquake of 26/30 October, 2016 occurrence.

\section{Detection of VLF/LF disturbances.}

In the frame of the International Network for Frontier Research on Earthquake Precursors (INFREP) [Biagi et al., 2011] a receiver in Thessaloniki, Greece $(40.59 \mathrm{~N}, 22,78 \mathrm{E})$ is monitoring the VLF transmitters based in Tavolara, Italy, Niscemi, Italy, and Le Blanc, France, [Skeberis et al., 2015]. The transmission paths of these transmitters to the Thesaloniki receiver passes over the broader area of the Amatrice erthquakes epicenters. Figure 11 displays the transmitters of the INFREP Network which are monitored by the receiver of Thessaloniki and Table 3 displays the sites and the transmitting frequencies of these transmitters.

\begin{tabular}{|c|c|c|c|}
\hline Freq. (KHz) & Station & Location & Lat/Lon \\
\hline 19.58 & GBZ & Anthorn, UK & $54^{\circ} 54^{\prime} 40^{\prime \prime} \mathrm{N} \quad 03^{\circ} 16^{\prime} 48^{\prime \prime} \mathrm{W}$ \\
\hline 20.27 & ICV & Tavolara, IT & $40^{\circ} 54^{\prime} 22^{\prime \prime}$ N. $09^{\circ} 42^{\prime} 48^{\prime \prime} \mathrm{E}$ \\
\hline 23.4 & HWU & Le Blanc, FR & $53^{\circ} 04^{\prime} 57^{\prime \prime}$ N. $07^{\circ} 36^{\prime} 55^{\prime \prime} \mathrm{E}$ \\
\hline 37.5 & ICE & Keflavik, ID & $64^{\circ} 01^{\prime} 00^{\prime \prime} \mathrm{N} 22^{\circ} 34^{\prime} 00^{\prime \prime} \mathrm{W}$ \\
\hline 45.9 & NSY & Niscemi, IT & $37^{\circ} 07^{\prime} 32^{\prime \prime} \mathrm{N} 14^{\circ} 26^{\prime} 11^{\prime \prime} \mathrm{E}$ \\
\hline 153 & $\mathrm{ROM}$ & Brasov, RO & $45^{\circ} 45^{\prime} 17^{\prime \prime} \mathrm{N} 25^{\circ} 36^{\prime} 24^{\prime \prime} \mathrm{E}$ \\
\hline 180 & TRT & Polalti, TR & $39^{\circ} 45^{\prime} 22^{\prime \prime} \mathrm{N} 43^{\circ} 25^{\prime} 05^{\prime \prime} \mathrm{E}$ \\
\hline 183 & EU1 & Felsberg, DE & $49^{\circ} 16^{\prime} 49^{\prime \prime} \mathrm{N} 06^{\circ} 40^{\prime} 41^{\prime \prime} \mathrm{E}$ \\
\hline 198 & CN1 & Berkaoui, DZ & $31^{\circ} 55^{\prime} 14^{\prime \prime} \mathrm{N} 05^{\circ} 04^{\prime} 03^{\prime \prime} \mathrm{E}$ \\
\hline 270 & CZE & Topolna, CZ & $49^{\circ} 07^{\prime} 25^{\prime} \mathrm{N} 17^{\circ} 30^{\prime} 52^{\prime \prime} \mathrm{E}$ \\
\hline
\end{tabular}

Table 3. The Transmitters oft he INFREP Network which are monitored by the Thessaloniki receiver. 


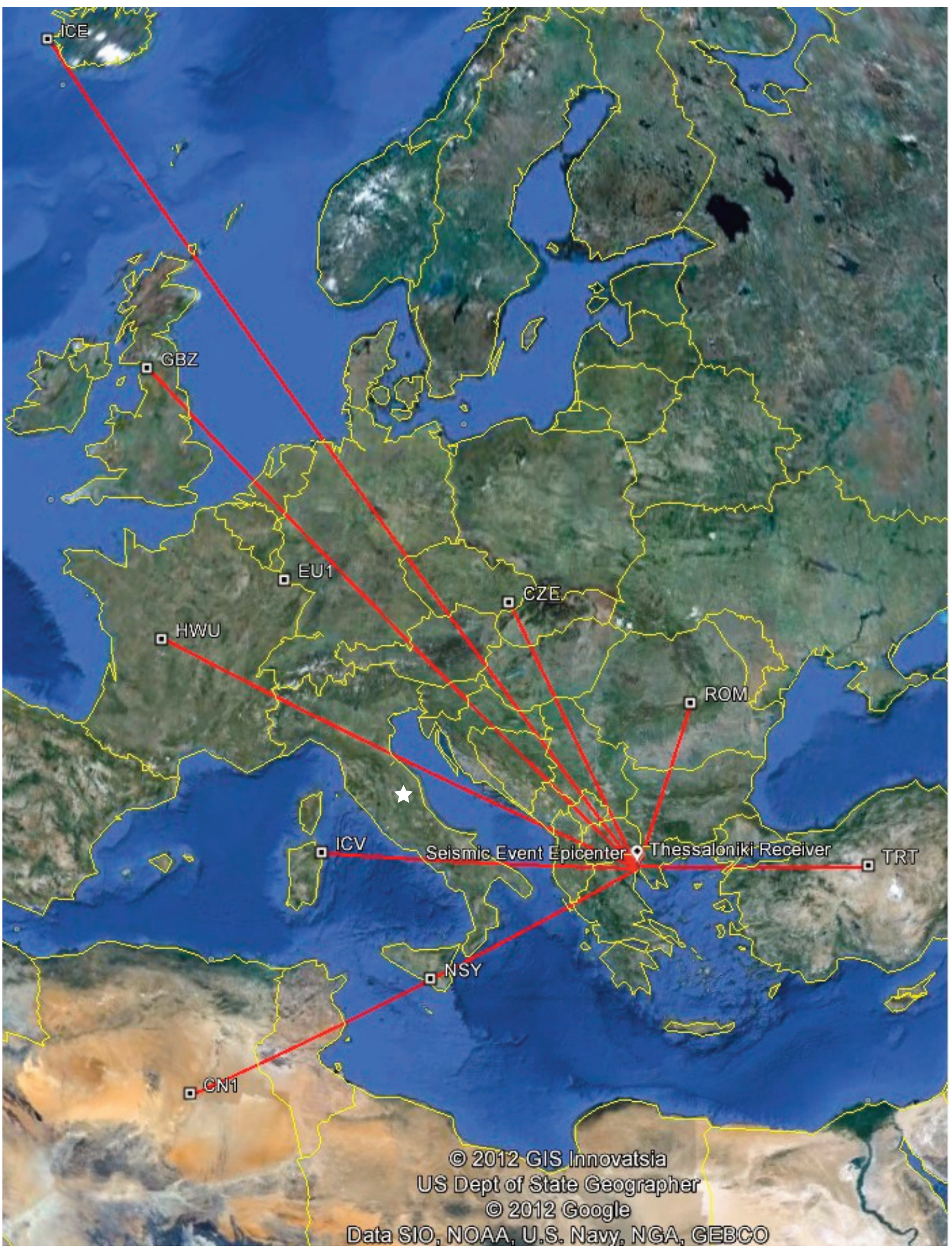

Figure 11. The INFREP Network. White star indicate Amatrice earthquakes epicenter. 


\section{Michael E. Contadakis et al.}

\subsection{Data Analysis}

The data are processed by the Hilbert Huang Transform (HHT) [Skeberis et al., 2015] which is a two step process. The first step of the process is the Complete Ensemble Empirical Mode Decomposition with Adaptive Noise (CEEMDAN) which devolves the signal to its Intrinsic Mode Functions (IMFs) and the second step of the process is a Hilbert Transform on the IMFs and subsequent production of the relevant spectra (Hilbert Amplitude Spectrum). In the produced spectra by selecting appropriate a time period before and after the earthquake, we can easily discern periods of calm and more importantly we can pinpoint areas which are of interest and can denote disturbances in the signals received during their propagation through the ionosphere. By eliminating other sources like geomagnetic storms (by going through the relevant geomagnetic indices of Ap and Kp) we can safely assume that the disturbances cause can be mainly attributed to the ionosphere, and are related to the seismic phenomenon in question.

During calm periods of no appreciable activity we can easily discern a normal pattern that is characterized by a diurnal fluctuation during the night and day cycles and no exceptional peaks that can be characterized as disturbances.

In the days prior to the earthquake, precursors can be seen as peaks that are breaking the pattern of normal fluctuations, with easily detectable peaks especially located in the higher frequency regions of the produced spectra. A priori, a point of interest is marked when amplitude is exceeding 0,25 after the normalization, and then an empirical pass is made, to correlate also with the frequency content of the disturbance.

In those peaks that anomalous behavior can be detected in the waveguide between transmitter and receiver that can be attributed to precursor phenomena prior to the occurrence the earthquake.

For the instance of the chain of earthquakes that occurred in Italy in August 2016, culminating in the earthquake of $24^{\text {th }}$ of August $2016\left(\mathrm{M}_{\mathrm{w}}=6.2\right)$ and in October 2016, culminating in the earthquake of $26^{\text {th }}$ of October $2016\left(\mathrm{M}_{\mathrm{w}}=6.1\right)$ and the earthquake of $30^{\text {th }}$ of October $2016\left(\mathrm{M}_{\mathrm{W}}=6.5\right)$ Figures 12 and 13 present the relevant spectra for the signals received in Thessaloniki from Tavolara, for August and October 2016, from Niscemi, for the same periods (Figure 14, Figure 15) and LeBlanc (Figure 16, Figure 17). As the spectra are seen on a period of 1 month for the purpose of giving a wider perspective of the phenomenon, in the presented figures we also provide jointly the diagrams of the maximum amplitude of each point, that provide a more direct but simple approach of the disturbances, and by combining them with the spectra able to provide a more comprehensive view.

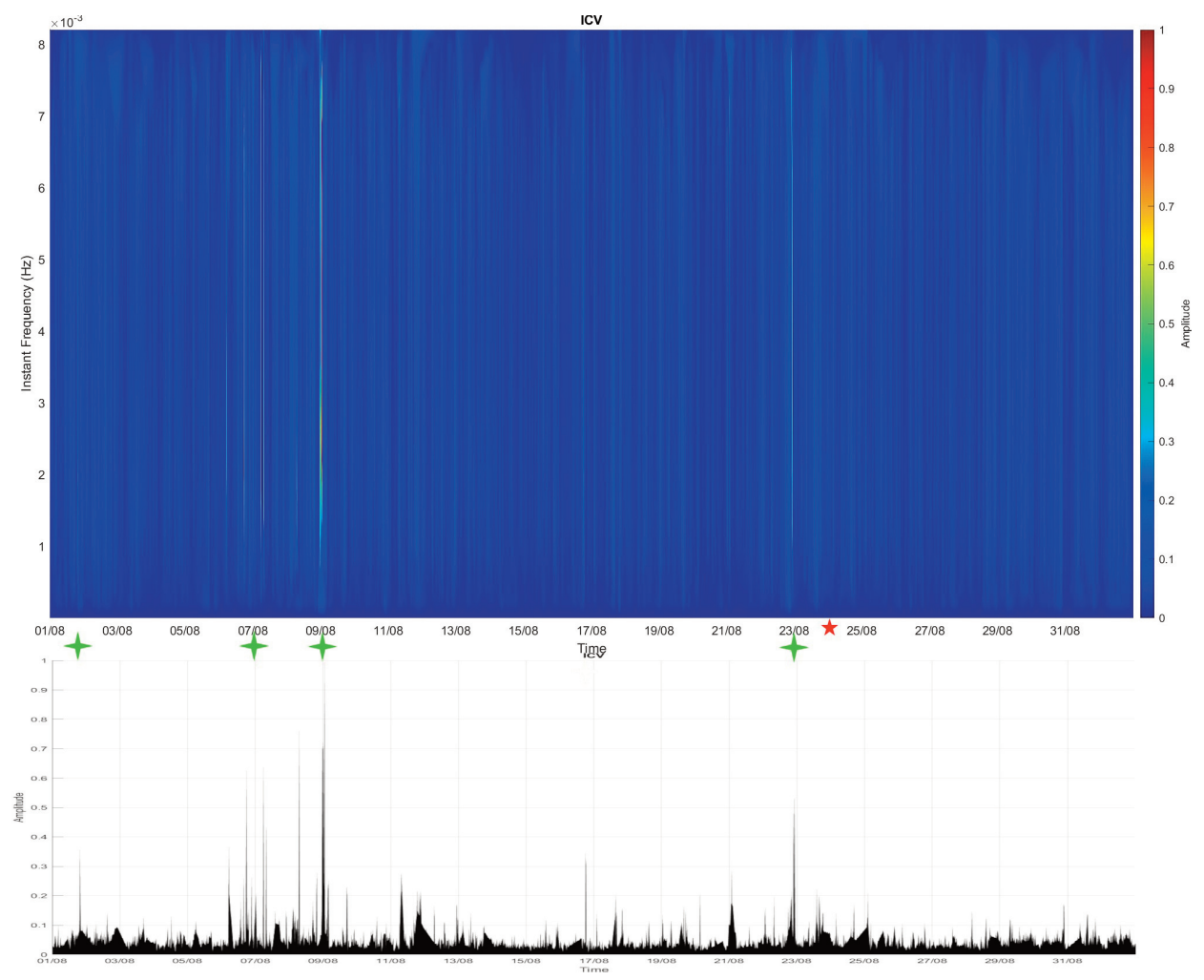

Figure 12. The spectrum of the signals received from Tavolara, Italy (ICV) (top) and maximum amplitude(bottom) - 01-082016 to 01-09-2016. Green stars denote the disturbances. Red star denotes the occurrence of the earthquakes. 
Ionospheric turbulence from TEC and VLF/LF

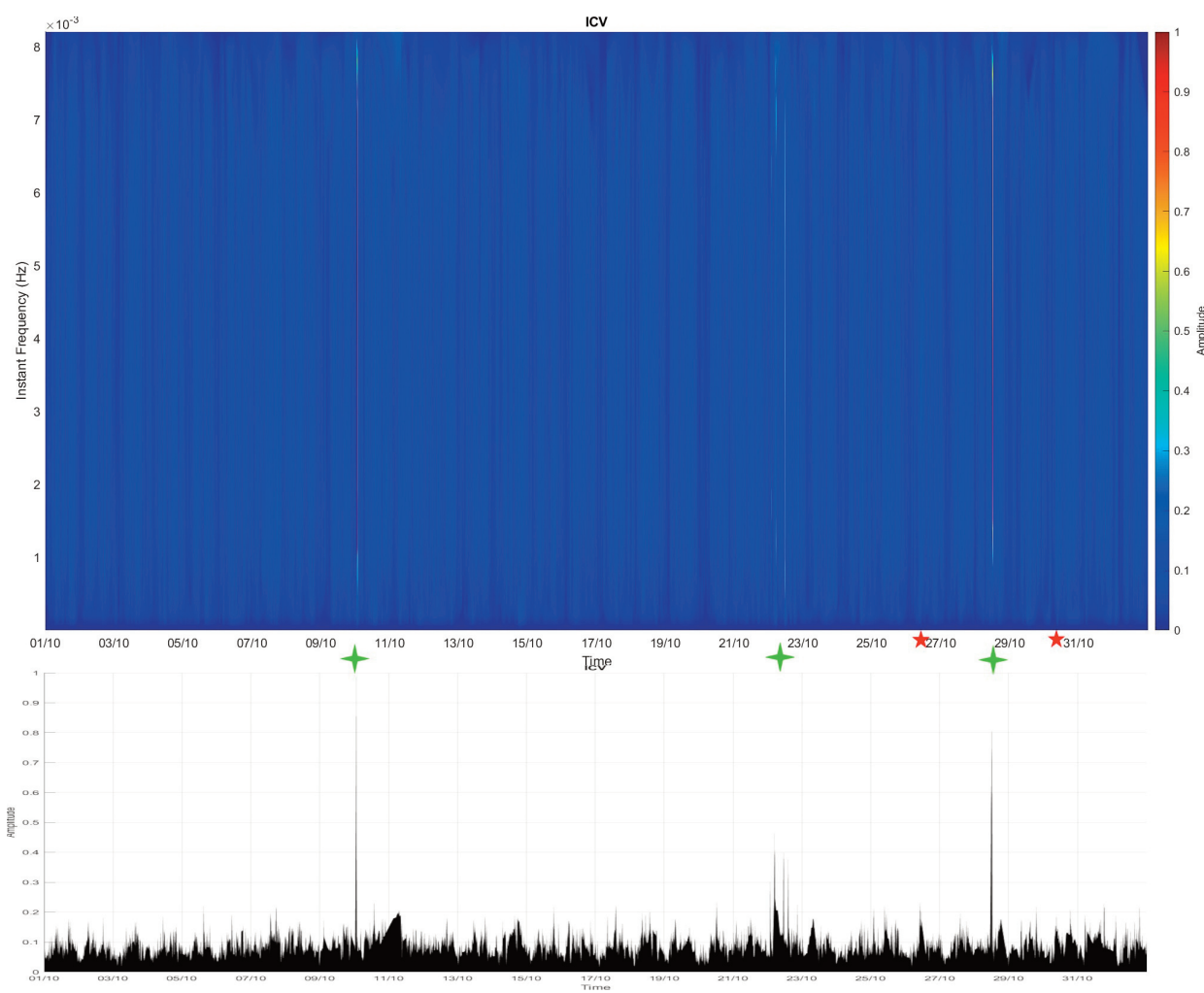

Figure 13. The spectrum of the signals received from Tavolara, Italy (ICV) (top) and maximum amplitude(bottom) - 01-102016 to 01-11-2016. Green stars denote the disturbances. Red star denote the occurrence of the earthquakes.

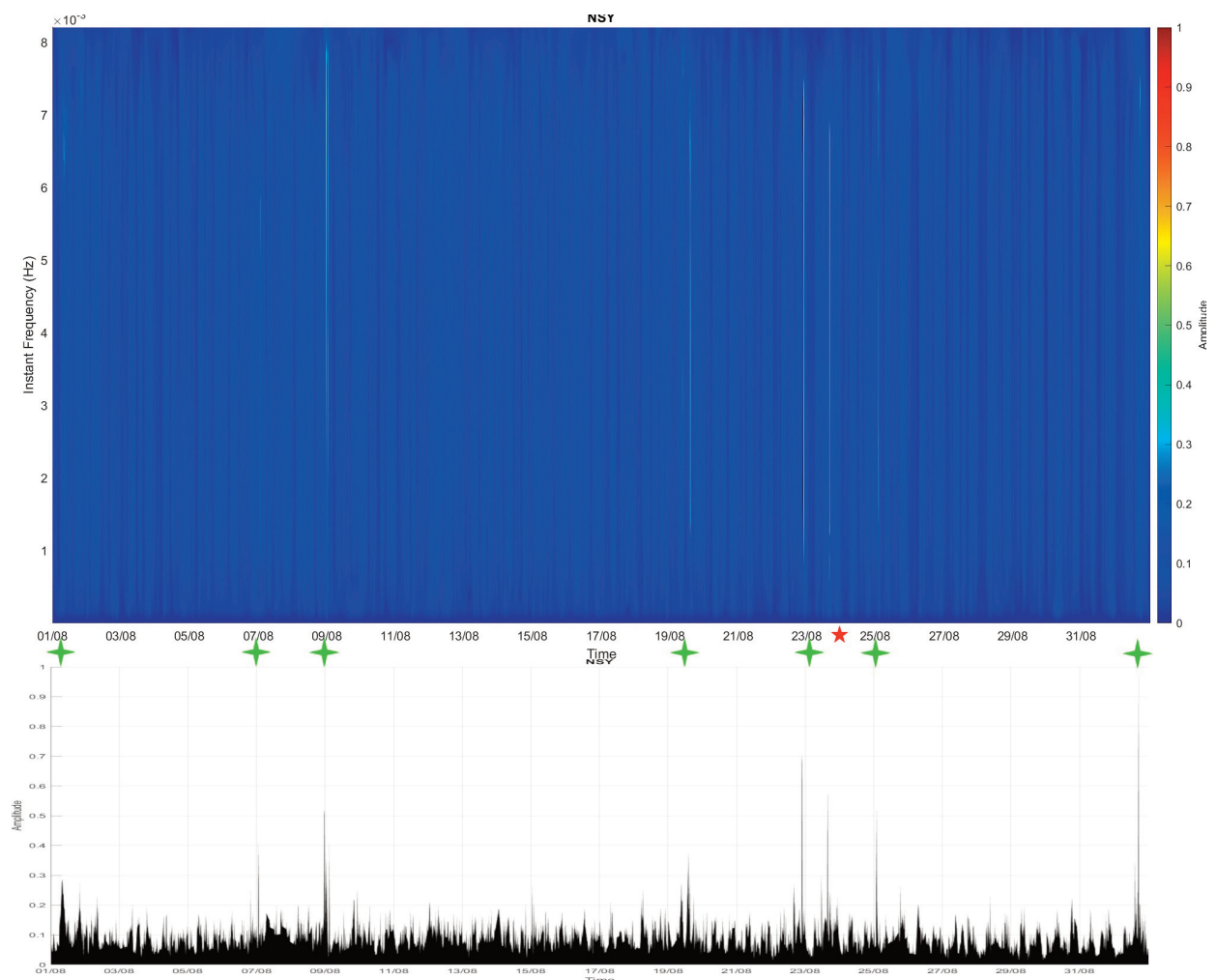

Figure 14. The spectrum of the signals received from Niscemi, Italy (NSY)(top) and maximum amplitude(bottom) - 01-082016 to 01-09-2016. Green stars denote the disturbances. Red star denotes the occurrence of the earthquakes. 
Michael E. Contadakis et al.

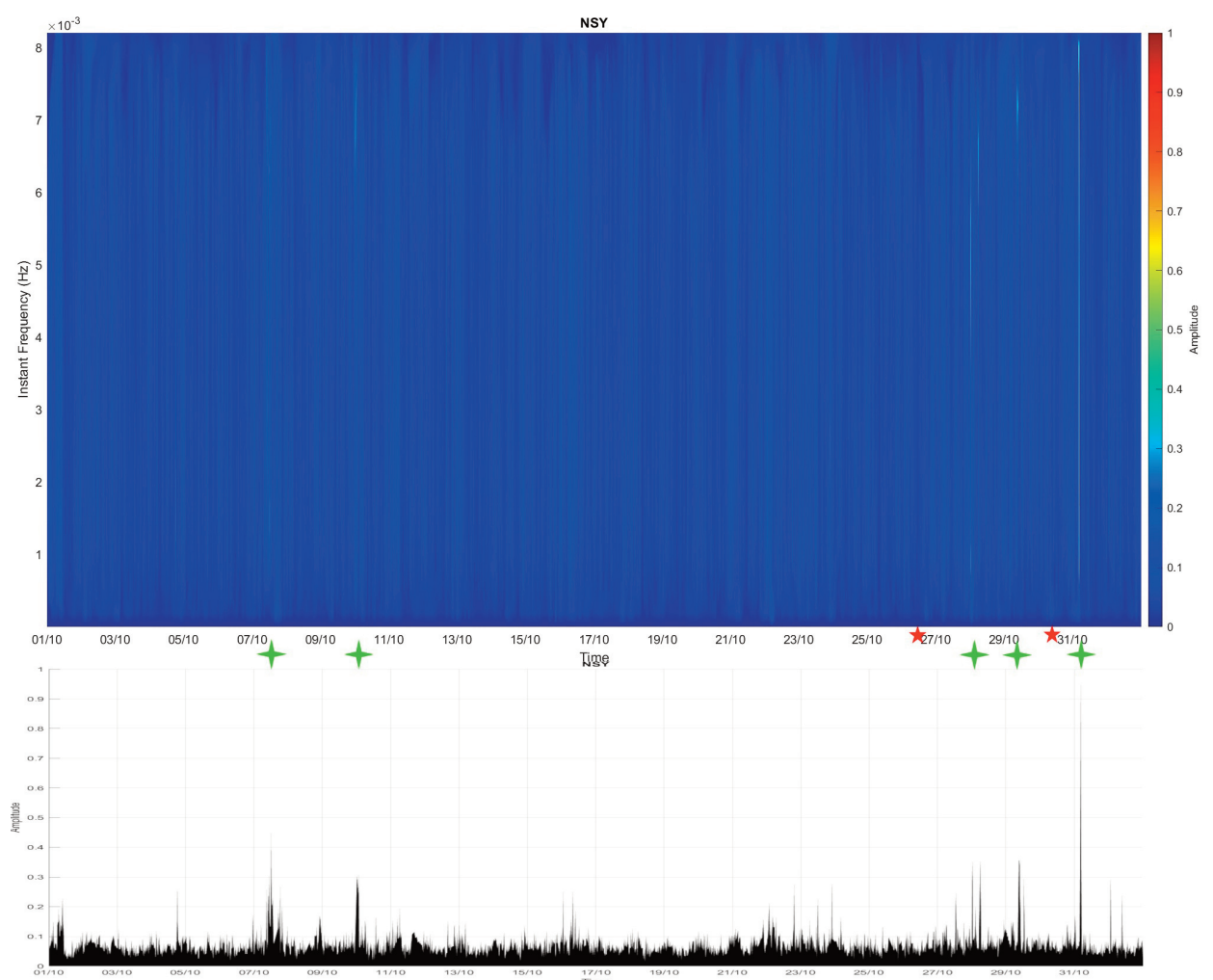

Figure 15. The spectrum of the signals received from Niscemi, Italy (NSY) (top) and maximum amplitude(bottom) - 01-102016 to 01-11-2016. Green stars denote the disturbances. Red stars denote the occurrence of the earthquakes.

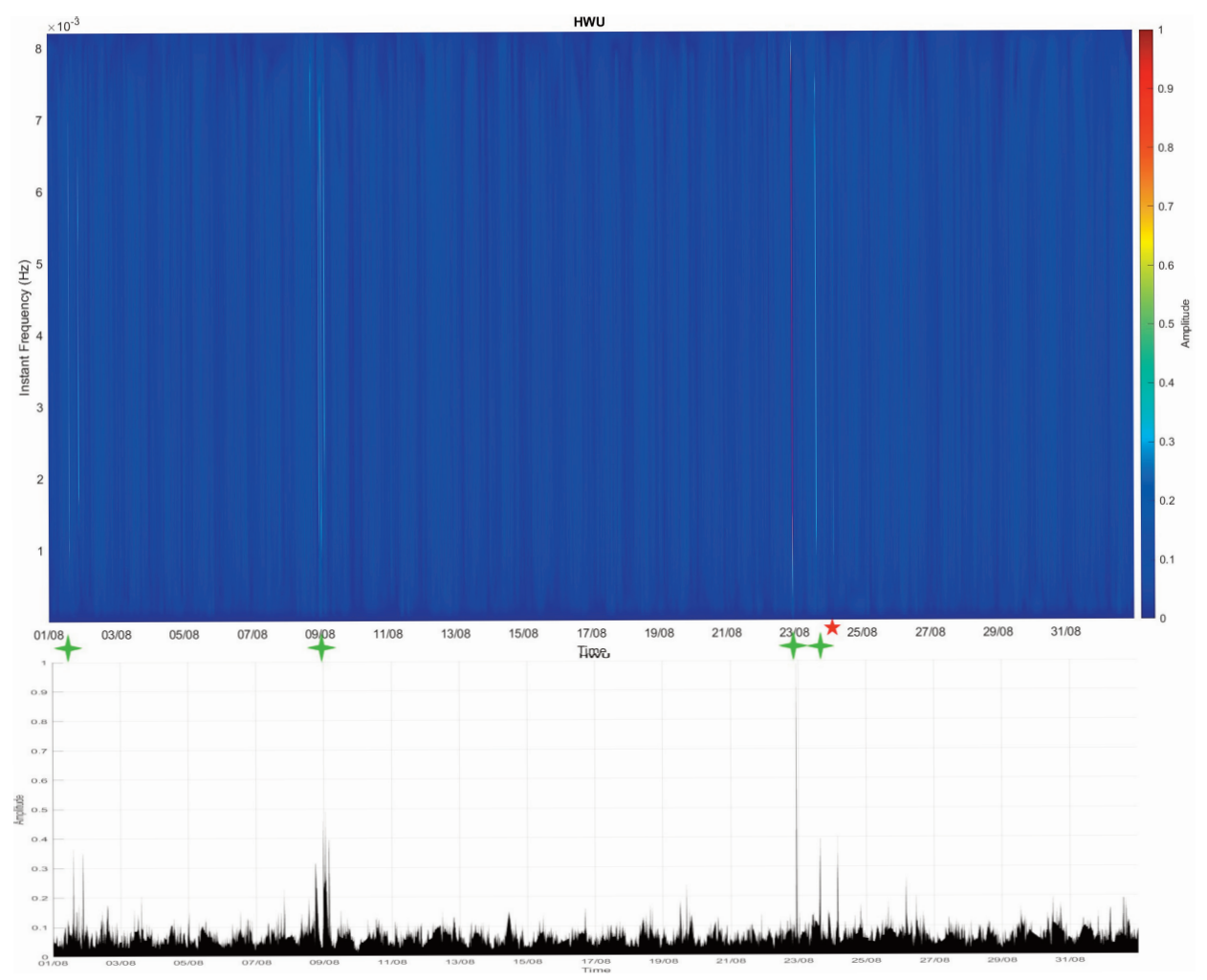

Figure 16. The spectrum of the signals received from LeBlanc, France(HWU) (top) and maximum amplitude(bottom) - 01-082016 to 01-09-2016. Green stars denote the disturbances. Red stars denote the occurrence of the earthquakes. 
Ionospheric turbulence from TEC and VLF/LF

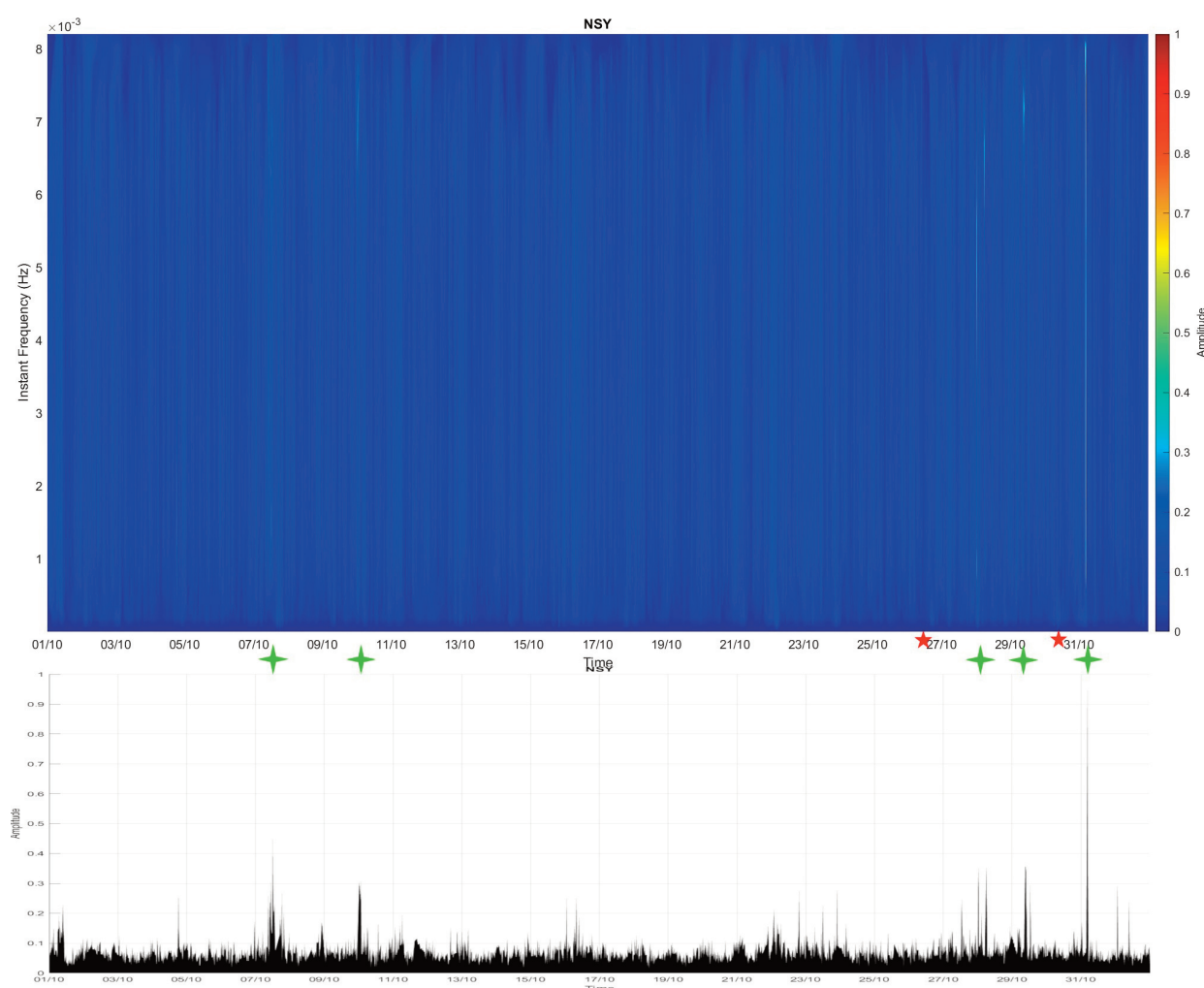

Figure 17. The spectrum of the signals received from LeBlanc, France (HWU) (top) and maximum amplitude(bottom) - 0110-2016 to 01-11-2016. Green stars denote the disturbances - Red stars denote the occurrence of the earthquakes.

\section{Concluding Remark}

It is shown that the frequency content of the ionospheric turbulence over the earthquake epicenter, deduced directly from GPS TEC observations or indirectly through the VLF transmission, moves to higher frequencies over the area of the epicenter of Amatrice earthquakes the last 15 days before the main shock and ranges between $0.001 \mathrm{~Hz}$ and $0.01 \mathrm{~Hz}$. This observational results are concistent with the explanation that this Ionospheric turbulence modulation is a result of the earthquake preparation process disturbances transmitted to Ionosphere by a LAIC mechanism. The inherent frequencies of the acoustic or gravity wave range between $0.003 \mathrm{~Hz}$ (period $\approx 5 \mathrm{~min}$ ) and $0.0002 \mathrm{~Hz}$ (period $\approx 100 \mathrm{~min}$ ), which according to Molchanov et al. [2004, 2006] correspond to the frequencies of the turbulence produced by tectonic activity during the earthquake preparation period. Then the modulated turbulence start to propagate, as gravity wave in the lower Ionospher waveguide. During this propagration the higher frequencies are progressively dumped. Thus observing the frequency content of the ionospheric turbidity we will observe a decrease of the higher limit of the turbitity frequency band.

\section{References}

Amato, A., B. Alessandrini, G.B. Cimini, A. Frepoli and G. Selvaggi (1993). Active and remnant subducted slabs beneath Italy: evidence from seismic tomography and seismicity. Ann. Geofys., 36 (2), 201-214.

D’Agostino, N., J.A. Jackson, F. Dramis and R. Funiciello (2001). Interactions between mantle upwelling, drainage evolution and active normal faulting: an example from the central Apennines (Italy). Geophys. J. Int., 147, 475-497.

Arikan, F., A. Yilmaz, O. Arikan, I. Sa Yin, M. Gurun, S.A. Yildirim (2009). Space Weather Activities of IONOLAB Group: TEC Mapi, Geoph. Res. Abstr., 11

P. F. Biagi, T. Maggipinto, F. Righetti, D. Loiacono, L. Schiavulli, T. Ligonzo, A. Ermini, I. A. Moldovan, A. S. Moldovan, 


\section{Michael E. Contadakis et al.}

A. Buyuksarac, H. G. Silva, M. Bezzeghoud, and M. E. Contadakis (2011). The European VLF/LF radio network to search for earthquake precursors: setting up and natural/man-made disturbances, Nat. Hazards Earth Syst. Sci., 11, 333-341

Cinque, A, A. Patacca, P. Scandone and M. Tozzi (1993). Quaternary kinematic evolution of the Southern Apennines. Relationships between surface geological features and deep lithospheric structures. Ann. Geofys., 36, 249-260

Contadakis, M.E., D. N. Arabelos, G. Asteriadis, S.D. Spatalas, C. Pikridas, C. (2008). TEC variations over the Mediterranean during the seismic activity period of the last quarter of 2005 in the area of Greece, Nat. Hazards and Earth Syst. Sci., 8, 1267-1276

Contadakis, M.E., D.N Arabelos, S.D., Spatalas, C. Pikridas (2012a). TEC variations over Southern Europe before and during the M6.3 Abruzzo earthquake of $6^{\text {th }}$ April 2009, Ann. Geophys., 55, 1, p. 83-93

Contadakis, M. E., D. N. Arabelos., G. Vergos, S.D. Spatalas, M. Skordilis (2015). TEC variations over the Mediterranean before and during the strong earthquake $(\mathrm{M}=6.5)$ of 12th October 2013 in Crete, Greece, Phys. Chem. Earth, 85, 9-16.

Duni, L., Sh.Kuka and N.Kuka, (2010) Local relations for converting $\mathrm{M}_{\mathrm{L}}$ to $\mathrm{M}_{\mathrm{W}}$ in southern-western Balkan region. ActaGeod. Geoph. Hung., 45(3), 317-323.

Hayakawa, M. (2011). On the fluctuation spectra of seismo-electromagnetic phenomena, Nat.Hazards Earth Syst.Sci., 11,301-308

Hayakawa, M., Y. Kasahara, T. Nakamura, Y. Hobara, A. Rozhnoi, M. Solovieva, O.A. Molchanov and V. Korepanov (2011). Atmospheric gravity waves as a possible candidate for seismo-ionospheric perturbations, J. Atmos.Electr., 32, 3, 129-140.

Hayakawa, M., T. Asano, A. Rozhnoi and M. Solovieva, (2018). Very-low- and low-frequency sounding of ionospheric perturbations and possible association with earthquakes, in "Pre-earthquake Processes: A multidisciplinary approach to earthquake prediction studies”, Ed. by D. Ouzounov et al., 277-304, AGU Book, Wiley.

Hobara, Y., F. Lefeuvre, M. Parrot and O. A. Molchanov (2005) Low-latitude ionospheric turbulence observed by Aureol-3 satellite, Annales Geophysicae, 23, 1259-1270

Kruse, S., and L. H. Royden (1994). Bending and unbending of an elastic lithosphere: the Cenozoic history of the Apennine and Dinarideforedeep basins. Tectonics, 13, 278-302.

Miyaki, K., M. Hayakawa and O.A. Molchanov (2002). The role of gravity waves in the lithosphere-atmosphereionosphere coupling, as revealed from the subionospheric LF propagation, in "Seismo Electromagnetics: Lithosphere-Atmosphere-Ionosphere Coupling”, Ed. by M. Hayakawa and O. A. Molchanov, TERRAPUB, Tokyo, 229-232.

Molchanov, O., P. F. Biagi., M. Hayakawa, A. Lutikov, S. Yunga, D. Iudin, S. Andreevsky., A. Rozhnoi, V. Surkov, V. Chebrov, E. Gordeev, A Schekotov, E. Fedorov (2004). Lithosphere-atmosphere-ionosphere coupling as governing mechanism for preseismic short-term events in atmosphere and ionosphere, Nat. Hazards Earth Syst. Sci., 4, 5/6, 757-767

Molchanov, O., A. Schekotov, M. Solovieva, E. Fedorov, V. Gladyshev, E. Gordeev, V. Chebrov., D. Saltykov, V. I. Sinitsin, K. Hattori, M. Hayakawa (2005). Near seismic effects in ULF fields and seismo-acoustic emission: statistics and explanation, Nat. Hazards Earth Syst. Sci., 5, 1-10,

Papazachos, B.C., E. M. Scordilis, D. G. Panagiotopoulos, C. B. Papazachos, and G.F. Karakaisis (2004). Global relations between seismic fault parameters and moment magnitude of earthquakes, Bull. Geol. Soc. Greece, XXXVI, 3, 1482-1489.

Patacca, E., R. Sartori and P. Scandone (1990). Tyrrhenian basin and Apennine arcs: kinematic relations since late Tortonian times. Mem. Soc. Geol. It., 45, 425-451.

Rozhnoi A., M. Solovieva, M. Parrot, M. Hayakawa, P.F. Biagi, K. Schwingenschuh (2012). Ionospheric turbulence from ground-based and satellite VLF/LF transmitter signal observations for the Simushir earthquake (November 15, 2006), Ann. Geophys., 55, 1, 2012; doi:10.4401/ag-5190

Scandone, P., (1996). Linea di Ricerca 2 “Sismotettonica”. In: Corsanego, A., Faccioli, E.Gavarini, C., Scandone, P., Slejko, D., Stucchi, M. (Eds.), L’attivita`del GNDT neltriennio 1993-1995. CNR-GNDT, Rome, pp. 67-96.

Scordilis, E.M., (2006). Empirical global relations converting $\mathrm{M}_{\mathrm{s}}$ and $\mathrm{m}_{\mathrm{b}}$ to moment magnitude. J. Seismol., 10, 225236.

Schuster, A., (1897). On lunar and solar periodicities of earthquakes, Proc. R.Soc. Lond., 61, 455-465 
Selvaggi, G., and A. Amato (1992). Subcrustal earthquakes in the northern Apennines (Italy): Evidence for a still active subduction? Geophys. Res. Lett., 19, 2127-2130.

Skeberis, C., Z. D. Zaharis, T. D. Xenos, S. Spatalas, D. N. Arabelos and M. E. Contadakis (2015). Time-frequency analysis of VLF for seismic-ionospheric precursor detection: Evaluation of Zhao-Atlas-Marks and HilbertHuang Transforms. Phys- Chem. Earth, Parts A/B/C, 85, 174-184

Sparkman, W., S. Van Der Lee and R. Van Der Hilst, (1993). Travel-time tomography of the European-Mediterranean mantle down to 1400km. Phys Earth Planet. Inter., 79, 3-74.

Tsampas, A., (2006). The critical earthquake model in low seismicity areas of Europe. MSc Thesis, Aristotle University of Thessaloniki, 135pp (in Greek).

Turcotte D.L. (1997). Fractal and Chaos in Geology and Geophysics (2 $2^{\text {nd }}$ Edition), Cambridge University Press, Cambridge U. K.

"CORRESPONDING AUTHOR: Michael E. CONTADAKIS,

Department of Geodesy and Surveying, Aristotle University of Thessaloniki, 